\title{
Prediction of Ship Motions on Waves using Marine Systems Simulator
}

\author{
${ }^{1}$ Vu Tai Tu, ${ }^{2}$ Nguyen Quang Hung, ${ }^{3} \mathrm{Chu}$ Anh My and ${ }^{4}$ Nguyen Thi Ngoc Hoa \\ ${ }^{1}$ General Department of Defence Industry, Vietnam \\ ${ }^{2}$ Academy of Military Science and Technology, CAPITI, Vietnam \\ ${ }^{3}$ Military Technical Academy, Vietnam \\ ${ }^{4}$ Ho Chi Minh City University of Transport, Vietnam
}

\begin{abstract}
Accurate modelling and simulation of ship motions in seaway is essential due to these results would be used to improve ship functions in aspect of safety and reliability in service, regularity and adequate operation. This study presents an overview of mathematical models in Marine Systems Simulator (MSS) which is a MATLAB/Simulink library and simulator for marine systems. This models simulate real-time six degree of freedom ship motions (pitch, heave, roll, surge, sway and yaw). The well-known US Navy combatant, DTMB 5415 test cases are used to verify and validate the accuracy of case studies.
\end{abstract}

Key words: Ship motions, waves, MSS, degree of freedom, regularity, MATAB/Simulink library

\section{INTRODUCTION}

When planning the designing of new vessels, it is essential to have a rational basis to evaluate the techno-economic of alternative designs. This evaluation should consider the vessel's operational performance in which the ship motion characteristics on waves are one of the most importance factors. Study ship motion characteristics provide information about the ship behaviors in seaway. These results would be used to improve ship functions in aspect of safety and reliability in service, regularity and adequate operation. In recent year, there are three general methods to predict ship motions on waves including: model test; full-scale measurements on ships at sea and theoretical methods (Bertram, 2012). All of the above approaches still have some restrictions. The first and the second methods are advance in providing high reliability results, however, these require highest cost and time consuming. The last method, though having lower reliability than the two previous ones, it requires the least cost and calculation time. Therefore, this is widely used in the initial design stage.

Depending on the assumption to simplify the fluid equations, there are several different approaches for prediction of ship motions on waves:

- Potential flow theory: panel method (Newman, 1992; Kring, 1994; Kim and Kim, 2011; Soding et al., 2014) and strip theory (Journee, 1992; Journee and Massie, 2001)
- Reynolds-Averaged Navier-Stoke Equation (RANSE) modeling (Carrica et al., 2011; Brunswig and El-Moctar, 2004)

- Marine system simulator (Smogeli et al., 2005; Perez et al., 2006)

In the above methods, the MSS method allows us to be able to simulate real-time six degree of freedom ship motions (pith, heave, roll, surge, sway and yaw). This is to be a fast generating prototype controllers approach based on simulink diagrams that run in real time on stand-alone computer systems for tests on scale models or full scale systems. In addition, this also provides the possibility of implementing hardware-in-theloop simulations (Perez et al., 2006). Moreover, it is essential for us in education.

This study presents an overview of Mathematical models in MSS which is a MATLAB/Simulink ${ }^{\circledR}$ library and simulator for marine systems. These models are applied to predict the ship motions on waves. The selected case study to verify and validate the models is a well-known US Navy combatant, DTMB 5415, its geometries and the experimental data for validation are taken from the (Fossen, 2002).

\section{MATERIALS AND METHODS}

Degrees of freedom: Similar to a 3D object, a vessel is free to move about six Degrees-of-Freedom (DOF). Thus, in order to determine its position and orientation it is essential to consider it in a six independent coordinates.

Corresponding Author: Vu Tai Tu, General Department of Defence Industry, Vietnam 


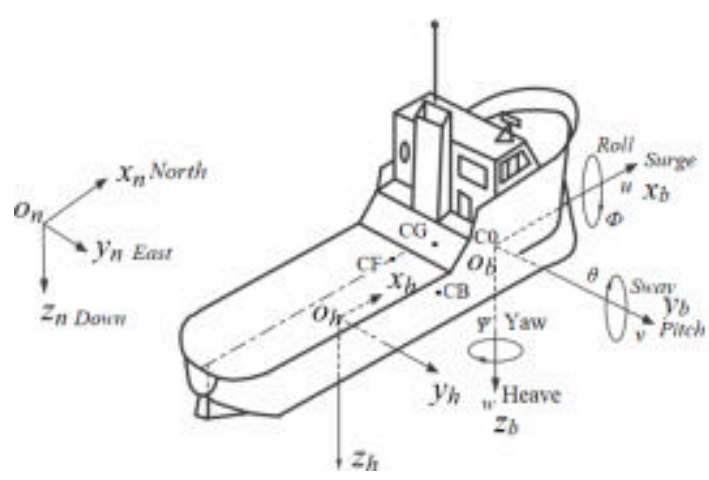

Fig. 1: Definition coordinate systems

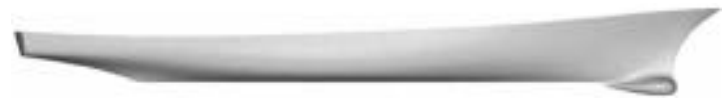

Fig. 2: Geometry of DTMB

Table 1: Nomenclature for the description of ship motion
\begin{tabular}{llccc} 
DOF & Name & $\begin{array}{c}\text { Forces and } \\
\text { moments }\end{array}$ & $\begin{array}{c}\text { Linear and } \\
\text { angular velocities }\end{array}$ & $\begin{array}{c}\text { Positions and } \\
\text { Euler angles }\end{array}$ \\
\hline 1 & Surge & $\mathrm{X}$ & $\mathrm{u}$ & $\mathrm{x}$ \\
2 & Sway & $\mathrm{Y}$ & $\mathrm{v}$ & $\mathrm{y}$ \\
3 & Heave & $\mathrm{Z}$ & $\mathrm{w}$ & $\mathrm{Z}$ \\
4 & Roll & $\mathrm{K}$ & $\mathrm{p}$ & $\phi$ \\
5 & Pitch & $\mathrm{M}$ & $\mathrm{q}$ & $\theta$ \\
6 & Yaw & $\mathrm{N}$ & $\mathrm{r}$ & $\psi$ \\
\hline
\end{tabular}

The three of those and their time derivatives are used to illustrate the ship position and translational movements along the axes: $x, y$ and $z$. Meanwhile, the rest of coordinates and their time derivatives are used to describe orientation and rotational motion, Fig. 1 and Table 1.

Coordinate systems: To describe the ship motions, it is necessary to consider three coordinates for defining the ship translations and three coordinates for defining the orientation ( $6 \mathrm{DOF})$. These coordinates are made up using two reference frames types: inertial frames and body fixed frames. Figure 1 presents the applying reference frames in MSS (Fossen, 2002).

NED (n-frame): The n-frame is assumed fixed on the Earth surface with the $\mathrm{X}_{\mathrm{n}}$-axis pointing North, the $\mathrm{Y}_{\mathrm{n}}$-axis pointing East and the $Z_{n}$-axis down of the Earth tangent plane.

BODY (b-frame): The body-fixed reference frame $0_{b} X_{b} Y_{b}$ $Z_{b}$ is a moving coordinate frame which is fixed to the vessel, Fig. 2. The origin $O_{b}$ lies at the intersection of the design waterline with the midship in the centreline plane. This point will be referred to as CO. The following reference points are defined with respect to $\mathrm{CO}$ :
CG-Center of Gravity; CB-Center of Buoyancy; CF-Center of Flotation (located a distance LCF from $\mathrm{CO}$ in the $\mathrm{x}$-direction).

Hydrodynamic frame (h-frame): The h-frame $0_{h} X_{h} Y_{h} Z_{h}$ is not fixed to the vessel; it is fixed to the equilibrium state (it moves at the average speed of the vessel). The h-frame is used in hydrodynamics to compute the forces and motion due to the interaction between the hull and the waves in particular scenarios.

The $n$-frame is used to define the position and orientation of the vessel while the linear and angular velocities are referred to the $b$-frame. They are described as follow: the $\mathrm{n}$-frame position $\mathrm{p}^{\mathrm{n}}=[\mathrm{n}, \mathrm{e}, \mathrm{d}]^{\mathrm{T}}$ and Euler angles: $\Theta=[\phi, \theta, \Psi]^{\mathrm{T}}$; body-fixed linear velocity: $\mathrm{v}_{0}{ }^{\mathrm{b}}=$ $[\mathrm{u}, \mathrm{v}, \mathrm{w}]^{\mathrm{T}}$; body-fixed angular velocity: $\omega_{0}{ }^{\mathrm{n}}=[\mathrm{p}, \mathrm{q}, \mathrm{r}]^{\mathrm{T}}$; body-fixed forces: $\mathrm{f}_{0}^{\mathrm{b}}[\mathrm{X}, \mathrm{Y}, \mathrm{Z}]^{\mathrm{T}}$ and body-fixed moments: $\mathrm{m}_{0}^{\mathrm{b}}=[\mathrm{K}, \mathrm{M}, \mathrm{N}]$. The $\mathrm{n}$-frame position and Euler angles are defined in terms of vector as follow:

$$
\eta=\left[\left(p^{\mathrm{n}}\right)^{\mathrm{T}}, \mathrm{T}^{\mathrm{T}}\right]^{\mathrm{T}}=[\mathrm{n}, \mathrm{e}, \mathrm{d}, \phi, \theta, \psi]^{\mathrm{T}}
$$

The b-frame linear velocities in $\mathrm{CO}$ and angular velocities are denoted as:

$$
v=\left[\mathrm{v}_{0}^{\mathrm{b}}, \omega_{0}^{\mathrm{n}}\right]^{\mathrm{T}}=[\mathrm{u}, \mathrm{v}, \mathrm{w}, \mathrm{p}, \mathrm{q}, \mathrm{r}]^{\mathrm{T}}
$$

The forces and moments with respect to the h-frame are denoted as:

$$
\tau_{\mathrm{RB}}=\left[\mathrm{f}_{0}^{\mathrm{b}}, \mathrm{m}_{0}^{\mathrm{b}}\right]^{\mathrm{T}}=[\mathrm{X}, \mathrm{Y}, \mathrm{Z}, \mathrm{K}, \mathrm{M}, \mathrm{N}]^{\mathrm{T}}
$$

Transformations between BODY and NED: Linear velocity transformation between BODY and NED is (Fossen, 2002):

$$
\mathrm{v}_{0}^{\mathrm{n}}=\mathrm{R}_{\mathrm{b}}^{\mathrm{n}}(\Theta) \mathrm{v}_{\mathrm{o}}^{\mathrm{b}}
$$

Where:

$$
\begin{aligned}
& \mathrm{R}_{\mathrm{b}}^{\mathrm{n}}(\Theta)=\mathrm{R}_{z, \psi} \mathrm{R}_{\mathrm{y}, \theta} \mathrm{R}_{\mathrm{z}, \phi}= \\
& {\left[\begin{array}{ccc}
\mathrm{c} \psi \mathrm{c} \theta & -\mathrm{s} \psi \mathrm{c} \phi+\mathrm{c} \psi \mathrm{s} \theta \mathrm{s} \phi & \mathrm{s} \psi \mathrm{s} \phi+\mathrm{c} \psi \mathrm{s} \theta \mathrm{c} \phi \\
\mathrm{s} \psi \mathrm{c} \theta & \mathrm{c} \psi \mathrm{c} \phi+\mathrm{s} \psi \mathrm{s} \theta \mathrm{s} \phi & -\mathrm{c} \psi \mathrm{s} \phi+\mathrm{s} \psi \mathrm{s} \theta \mathrm{c} \phi \\
-\mathrm{s} \theta & \mathrm{c} \theta \mathrm{s} \phi & \mathrm{c} \theta \mathrm{c} \phi
\end{array}\right]}
\end{aligned}
$$

The rotation matrix can be obtained using MSS toolbox as:

$$
\mathrm{R}=\operatorname{Rzyx}(\text { phi, theta, psi) }
$$

Angular velocity transformation between BODY and NED is (Fossen, 2002): 


$$
\dot{\Theta}=\mathrm{T}_{\Theta}(\Theta) \omega_{\mathrm{nb}}^{\mathrm{b}}
$$

Where:

$$
\mathrm{T}_{\Theta}(\Theta)=\left[\begin{array}{ccc}
1 & \mathrm{~s} \phi t \theta & \mathrm{c} \phi t \theta \\
0 & \mathrm{c} \phi & -\mathrm{s} \phi \\
0 & \mathrm{~s} \phi / \mathrm{c} \theta & \mathrm{c} \phi / \mathrm{c} \theta
\end{array}\right]
$$

Six DOF kinematic equations: The six DOFs kinematic equations can be expressed in vector form as:

$$
\dot{\eta}=\mathrm{J}(\eta) \nu
$$

Where:

$$
J(\eta)=\left[\begin{array}{cc}
R_{b}^{n}(\Theta) & 0_{3 \times 3} \\
0_{3 \times 3} & T_{\Theta}(\Theta)
\end{array}\right]
$$

The transformation matrix $\mathrm{J}$ and its elements $\mathrm{J}_{1}=\mathrm{R}_{\mathrm{b}}{ }_{\mathrm{n}}(\Theta)$ and $\mathrm{J}_{2}=\mathrm{T}_{\Theta}(\Theta)$ can be computed by using the MSS toolbox command as follow:

$$
\left[\mathrm{J}, \mathrm{J}_{1}, \mathrm{~J}_{2}\right]=\text { Eulerang }(\text { phi, theta, psi) }
$$

Dynamics: The ship dynamics research has mainly been focused on maneuvering and seakeeping. Maneuvering study ship motions in the case of wave excitation absence (in calm water). Meanwhile, seakeeping tends to study ship motion at constant course and speed with the presence of wave excitation. In this study, the $6 \mathrm{DOF}$ nonlinear dynamic equations of motion is derived as follows:

$$
\begin{aligned}
& \mathrm{M}_{\mathrm{RB}} \dot{v}+\mathrm{C}_{\mathrm{RB}}(v) \nu+\mathrm{M}_{\mathrm{A}} \dot{v}_{\mathrm{r}}+\mathrm{C}_{\mathrm{A}}(v) \nu_{\mathrm{r}}+ \\
& +\mathrm{D}(\nu) \nu_{\mathrm{r}}+\mu+\mathrm{g}(\eta)=\tau+\tau_{\mathrm{w}}
\end{aligned}
$$

Where:

$\mathrm{M}_{\mathrm{RB}} \quad=$ The rigid-body inertia Matrix

$\mathrm{C}_{\mathrm{RB}}(v)=$ The rigid-body Coriolis-centripetal matrix

$\mathrm{M}_{\mathrm{A}} \quad=$ The added mass inertia Matrix

$\mathrm{C}_{\mathrm{A}}(v)=$ The added mass Coriolis-centripetal matrix

$\mathrm{D}(v)=$ The damping matrix

$\mu=$ An additional term representing the fluid memory effect

$g(\eta)=$ The vector of gravitational buoyancy forces and moments

$\tau=$ The vector of control inputs

$\tau_{\mathrm{w}} \quad=$ The vector of environmental disturbances (wind, waves and currents)

Rigid-body equations of motion: The rigid-body dynamics can be expressed in a vectorial setting as:

$$
\mathrm{M}_{\mathrm{RB}} \dot{v}+\mathrm{C}_{\mathrm{RB}}(v) v=\tau_{\mathrm{RB}}
$$

where, $v=[\mathrm{u}, \mathrm{v}, \mathrm{w}, \mathrm{p}, \mathrm{q}, \mathrm{r}]^{\mathrm{T}}$ is the generalized velocity vector decomposed in the $b$-frame and $\tau_{R B}=[X, Y, Z, K$,
$\mathrm{M}, \mathrm{N}]^{\mathrm{T}}$ is a generalized vector of external forces and moments. The rigid-body system inertia Matrix $M_{R B}$ can be determined as:

$$
\mathrm{M}_{\mathrm{RB}}=\left[\begin{array}{cc}
\mathrm{mI}_{3 \times 3} & -\mathrm{mS}\left(\mathrm{r}_{\mathrm{g}}^{\mathrm{b}}\right) \\
\mathrm{mS}\left(\mathrm{r}_{\mathrm{g}}^{\mathrm{b}}\right) & \mathrm{I}_{0}
\end{array}\right]
$$

This matrix can be computed in MATLAB as:

$$
M_{\mathrm{RB}}=\left[\mathrm{m}^{*} \operatorname{eye}(3)-\mathrm{m}^{*} \operatorname{Smtrx}\left(\mathrm{r}_{-} \mathrm{g}\right) ; \mathrm{m}^{*} \operatorname{Smtrx}\left(\mathrm{r}_{\text {_g }}\right) \mathrm{Ic}\right]
$$

The Coriolis-centripetal matrix $\mathrm{C}_{\mathrm{RB}}(v)$ can be computed from $\mathrm{M}_{\mathrm{RB}}$ as follows:

$$
C(v)=\left[\begin{array}{cc}
0_{3 \times 3} & -S\left(M_{11} v_{1}+M_{12} v_{2}\right) \\
-S\left(M_{11} v_{1}+M_{12} v_{2}\right) & -S\left(M_{21} v_{1}+M_{22} v_{2}\right)
\end{array}\right]
$$

where, $v_{1}=[\mathrm{u}, \mathrm{v}, \mathrm{w}]^{\mathrm{T}}, v_{2}=[\mathrm{p}, \mathrm{q}, \mathrm{r}]^{\mathrm{T}}$. Using MSS toolbox, we have the command:

$$
\mathrm{C}_{\mathrm{RB}}=\mathrm{m} 2 \mathrm{c}(\mathrm{MRB}, \mathrm{nu})
$$

Restoring forces: The restoring forces of surface ships depend on its metacentric height, the location of the center of gravity CG and the center of buoyancy CB as well as the form and the size of the waterplane area. Let $A_{w p}$ denote the water plane area, $G_{T}$ is transverse metacentric height, $\mathrm{GM}_{\mathrm{L}}$ is the longitudinal metacentric height. The restoring forces and moments are determined as:

$$
\mathrm{g}(\eta)=\left[\begin{array}{c}
-\rho \mathrm{g} \int_{0}^{z} \mathrm{~A}_{\mathrm{wp}}(\xi) \mathrm{d} \xi \sin \theta \\
\rho \mathrm{g} \int_{0}^{z} \mathrm{~A}_{\mathrm{wp}}(\xi) \mathrm{d} \xi \cos \theta \sin \phi \\
\rho \mathrm{g} \int_{0}^{z} \mathrm{~A}_{\mathrm{wp}}(\xi) \mathrm{d} \xi \cos \theta \cos \phi \\
\rho g \nabla \mathrm{GM}_{\mathrm{T}} \sin \phi \cos \theta \cos \phi \\
\rho g \nabla \mathrm{GM}_{\mathrm{L}} \sin \theta \cos \theta \cos \phi \\
\rho \mathrm{g} \nabla\left(-\mathrm{GM}_{\mathrm{L}} \cos \theta+\mathrm{GM}_{\mathrm{T}}\right) \sin \phi \sin \theta
\end{array}\right]
$$

For surface vessels with small roll and pitch angles, it is convenient to use a linear approximation:

$$
\mathrm{g}(\eta) \approx \mathrm{G} \eta
$$

Where:

$$
\mathrm{G}=\operatorname{diag}\left\{0,0, \rho g \mathrm{~A}_{\mathrm{wp}}(0), \rho g \nabla \mathrm{GM}_{\mathrm{T}}, \rho g \nabla \mathrm{GM}_{\mathrm{L}}, 0\right\}
$$

Reference frame of seakeeping: According to seakeeping theory, the ship motions studies are performed by assuming that it can be expressed as superposing the motion of an equilibrium state and perturbations. The 
equilibrium is identified by a steady heading angle $\Psi$ and speed U. The perturbations are illustrated through zero-mean oscillatory components induced by first-order wave excitations. Thus, the motions are generally, described by using an equilibrium or reference frame of seakeeping.

Under the act of waves, the ship is to be moved from its equilibrium position and the point will fluctuate around its equilibrium position. The equilibrium state is defined by a steady heading and speed:

$$
\begin{aligned}
\mathbf{v}_{\mathrm{hn}}^{\mathrm{h}} & =\left[\begin{array}{lll}
\mathrm{U} \cos \bar{\psi} & \mathrm{U} \sin \bar{\psi} & 0
\end{array}\right]^{\mathrm{T}} \\
\mathrm{w}_{\mathrm{hn}}^{\mathrm{h}} & =\left[\begin{array}{lll}
0 & 0 & 0
\end{array}\right]^{\mathrm{T}} \\
\Theta_{\mathrm{hn}} & =\left[\begin{array}{lll}
0 & 0 & \bar{\psi}
\end{array}\right]^{\mathrm{T}}
\end{aligned}
$$

The velocity of h-frame with respect to $n$-frame expressed in h-frame is as follow:

$$
\mathrm{v}_{\mathrm{hn}}^{\mathrm{h}}=\mathrm{R}_{\mathrm{n}}^{\mathrm{h}}\left(\Theta_{\mathrm{hn}}\right) \mathrm{v}_{\mathrm{hn}}^{\mathrm{n}}=\left[\begin{array}{lll}
\mathrm{U} & 0 & 0
\end{array}\right]^{\mathrm{T}}
$$

It is common to denote the perturbation coordinates by:

$$
\xi=\left[\begin{array}{llllll}
\xi_{1} & \xi_{2} & \xi_{3} & \xi_{4} & \xi_{5} & \xi_{6}
\end{array}\right]^{\mathrm{T}}
$$

where, $\Theta_{\mathrm{hb}}=\left[\begin{array}{lll}\xi_{4} & \xi_{5} & \xi_{6}\end{array}\right]^{\mathrm{T}}=\left[\begin{array}{lll}\phi & \theta & \psi-\bar{\psi}\end{array}\right]$. The generalized velocity transformation between the h-frame and b-frame is:

$$
\dot{\xi}=\mathrm{J}^{*}\left(\Theta^{*}\right) \nu
$$

For most applications, the roll and pitch oscillations will be small, i.e, $\Theta \approx 0$, then $J^{*} J^{*}(0)=H\left(r_{h}^{b}\right)$ is a constant matrix.

Hydrodynamic forces: Using the $h$-frame, the dynamics of rigid-body can be rewritten, under an assumption that the Coriolis and centripetal forces caused by a rotating b-frame and added mass are neglected as:

$$
\mathrm{M}_{\mathrm{RB}}^{*} \ddot{\xi}=\tau_{\mathrm{H}}^{*}+\tau^{*}
$$

where, $\mathrm{M}_{\mathrm{RB}}{ }^{*}=\left(\mathrm{J}^{*}\right)^{-\mathrm{T}} \quad \mathrm{M}_{\mathrm{RB}}=(\mathrm{J})^{*} \cdot 1$ The generalized hydrodynamic forces in the s-frame can be expanded as:

$$
\tau_{\mathrm{H}}^{*}=\tau_{\mathrm{hh}}^{*}+\tau_{\text {hyd }}^{*}+\tau_{\mathrm{W}}^{*}
$$

Where:

$\tau_{h h}^{*}=$ The generalized hydrostatic force

$\tau_{\text {hyd }}^{*}=$ The generalized hydrodynamic force

$\tau_{\mathrm{W}}^{*}=$ The external forces
The generalized hydrostatic forces are written as:

$$
\tau_{\mathrm{hh}}^{*}=-\mathrm{g}^{*}(\xi)=\left(\mathrm{J}^{*}\right)^{-\mathrm{T}} \mathrm{g}(\eta)
$$

The radiation-induced hydrodynamic forces in an ideal fluid can be related to frequency-dependent added mass and potential damping:

$$
\tau_{\text {hyd }}=-\mathrm{A}^{*}(\omega) \dot{\xi}-\mathrm{B}^{*}(\omega) \dot{\xi}
$$

The frequency-dependent terms and can be removed by writing the equations of motions in the following form:

$$
\left(\mathrm{M}_{\mathrm{RB}}^{*}+\mathrm{A}^{*}(\infty)\right) \ddot{\xi}+\mathrm{B}^{*}(\infty) \dot{\xi}+\mu^{*}+\mathrm{g}^{*}(\xi)=\tau_{\mathrm{W}}^{*}+\tau^{*}
$$

where, $\mu^{*}$ can be approximated by a linear state-space model:

$$
\mu^{*}=\mathrm{C}_{\mathrm{r}} \chi+\mathrm{D}_{\mathrm{r}} \dot{\xi} ; \dot{\chi}=\mathrm{A}_{\mathrm{r}} \chi+\mathrm{B}_{\mathrm{r}} \dot{\xi} ; \quad \chi(0)=0
$$

By transforming to the b-frame and taking Coriolis and centripetal forces into account, the resulting model can be described as:

$$
\mathrm{M} \dot{v}+\mathrm{C}(\nu) \nu+\mathrm{D} v+\mathrm{g}(\eta)+\mu=\tau+\tau_{\mathrm{w}}
$$

where, $M=M_{R B}+M_{A}, C=C_{R B}+C_{A}, \mu=J^{* T} \mu^{*}$. The added mass Matrix $M_{A}$ is considered as constant and symmetric, $\mathrm{C}_{\mathrm{A}}$ can be obtained using command in MSS toolbox:

$$
\mathrm{CA}=\mathrm{m} 2 \mathrm{c}(\mathrm{MA}, \mathrm{nu})
$$

\section{Environmental models}

Wave model: Ocean waves are irregular sea states which may be described by a wave Spectrum $S(\omega, \beta)=S(\omega)$ D $(\beta)$ where the frequency Spectrum $S(\omega)$ describes the energy distribution of the sea state over different frequencies $\omega$ and the spreading function $D(\beta)$ describes the distribution of wave energy over direction $\beta$ in the $\mathrm{n}$-frame. For simulation, the sea state is realized as superposition of harmonic components extracted from the wave spectrum where the harmonic component $j$ is defined in terms of the amplitude $s_{j}$, frequency $\omega_{j}$, direction $\beta_{\mathrm{j}}$ and random phase $\phi_{\mathrm{j}}$.

Load wave model: The first-order wave forces in the

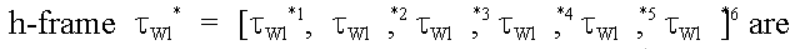
calculated from the force Transfer functions $\mathrm{T}^{\mathrm{i}}\left(\omega_{\mathrm{j}}, \beta_{\mathrm{j}}\right)$ for $\mathrm{DOF} i$. The total force is the sum over $\mathrm{N}$ harmonic wave components, for $\mathrm{i}=1.6$ : 


$$
\tau_{\mathrm{w} 1}^{*_{\mathrm{i}}}=\sum_{\mathrm{j}=1}^{\mathrm{N}} \zeta_{\mathrm{j}}\left|\mathrm{T}_{\mathrm{j}}^{\mathrm{i}}\right| \cos \left(\omega_{\mathrm{j}} \mathrm{t}+\phi_{\mathrm{j}}+\arg \left(\mathrm{T}_{\mathrm{j}}^{\mathrm{i}}\right)\right)
$$

The wave drift loads make up a significant portion of the total excitation forces. The total wave drift loads is given by:

$$
\tau_{\mathrm{w} 2}^{\mathrm{i}}=\sum_{\mathrm{j}=1}^{\mathrm{N}} \sum_{\mathrm{k}=1}^{\mathrm{N}} \zeta_{\mathrm{j}} \zeta_{\mathrm{k}} \mathrm{T}_{\mathrm{jk}}^{\mathrm{i} 2} \cos \left(\left(\omega_{\mathrm{k}}-\omega_{\mathrm{j}}\right) \mathrm{t}+\varphi_{\mathrm{k}}-\varphi_{\mathrm{j}}\right)
$$

where, $\varphi_{j}$ is a phase angle, $T_{j k}{ }^{i 2}=T_{k j}{ }^{i 2} i / 2\left(T_{j j}{ }^{i 2}+T_{k k}{ }^{i 2}\right)$. In b-frame, the wave-drift forces are calculated as:

$$
\tau_{\mathrm{w} 2}=\mathrm{H}^{\mathrm{T}}\left(\mathrm{r}_{\mathrm{w} 2}^{\mathrm{b}}\right)\left[\tau_{\mathrm{w} 2}^{1}, \ldots, \tau_{\mathrm{w} 2}^{6}\right]^{\mathrm{T}}
$$

\section{RESULTS AND DISCUSSION}

Reference vessel: The studied vessel in this study is a US Navy combatant DTMB, shown in Fig. 2 with its characteristics given in Table 2 . The main reason of using this hull is that the hull geometry is a public domain and extensive database of seakeeping test exists at different Froude numbers and sea states that were carried out by Ship Design and Research Centre CTO S.A, Poland (Anonymous, 2017).

Test cases conditions: Computations were performed for the following conditions:
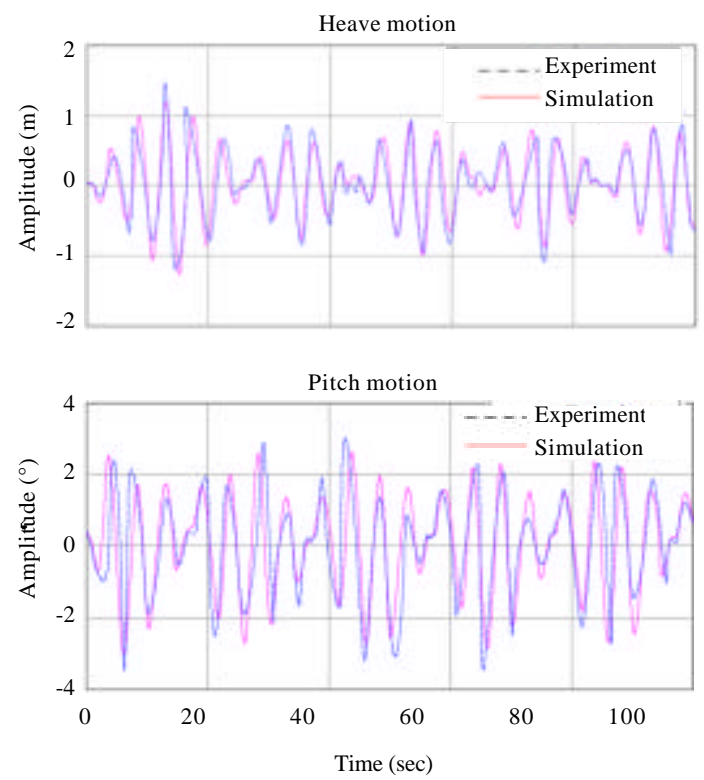

Fig. 3: Continue
- Vessel condition: draft $\mathrm{T}=6.15 \mathrm{~m} ; \mathrm{VCG}=7.55 \mathrm{~m}$; Trim $=0$

- Vessel speed: 18 knots

- Environmental condition: The sea state was generated from the JONSWAP spectrum with significant wave height $\mathrm{H}_{s}=4.25 \mathrm{~m}$; modal periods $\mathrm{Tp}=9.8 \mathrm{sec}$; spectrum peakedness factor in head sea condition

The simulation based on MATLAB/Simulink using MSS toolbox. The results for six motions of DTMB vessel when considering the influences of wave are given in Fig. 3 for surge, sway, heave, roll, pitch and yaw motion, respectively. It can be observed from the figures that the simulation results show good agreement with the experimental data for heave roll and pitch cases.

Table 2: Main particulars of the DTMB

\begin{tabular}{llll}
\hline Particulars & Symbol & Unit & Full-scale \\
\hline Length between perpendiculars & $\mathrm{L}_{\mathrm{PP}}$ & {$[\mathrm{m}]$} & 142.00 \\
Length of waterline & $\mathrm{L}_{\mathrm{WL}}$ & {$[\mathrm{m}]$} & 142.20 \\
Breadth at waterline & $\mathrm{B}$ & {$[\mathrm{m}]$} & 19.06 \\
Draught: fore & $\mathrm{T}_{\mathrm{F}}$ & {$[\mathrm{m}]$} & 6.15 \\
Draught: aft & $\mathrm{T}_{\mathrm{A}}$ & {$[\mathrm{m}]$} & 6.15 \\
Displacement volume & $\mathrm{L}$ & {$\left[\mathrm{m}^{3}\right]$} & 8447 \\
Area of wetted surface & $\mathrm{S}$ & {$\left[\mathrm{m}^{2}\right]$} & 2979 \\
Relative longitudinal Centre of & $\mathrm{L}_{\mathrm{CB}} / \mathrm{L}_{\mathrm{PP}}$ & {$[\%]$} & -0.55 \\
Buoyancy from midship section, & & & \\
"+" to fore & & & \\
Block coefficient & $\mathrm{C}_{\mathrm{B}}$ & {$[-]$} & 0.508 \\
Midship section coefficient & $\mathrm{C}_{\mathrm{M}}$ & {$[-]$} & 0.819 \\
Longitudinal prismatic coefficient & $\mathrm{C}_{\mathrm{P}}$ & {$[-]$} & 0.620 \\
Waterplane area coefficient & $\mathrm{C}_{\mathrm{WP}}$ & {$[-]$} & 0.774 \\
Transverse metacentric height & $\mathrm{GM}_{\mathrm{T}}$ & {$[\mathrm{m}]$} & 1.95 \\
Longitudinal metacentric height & $\mathrm{GM}_{\mathrm{L}}$ & {$[\mathrm{m}]$} & 266 \\
\hline
\end{tabular}
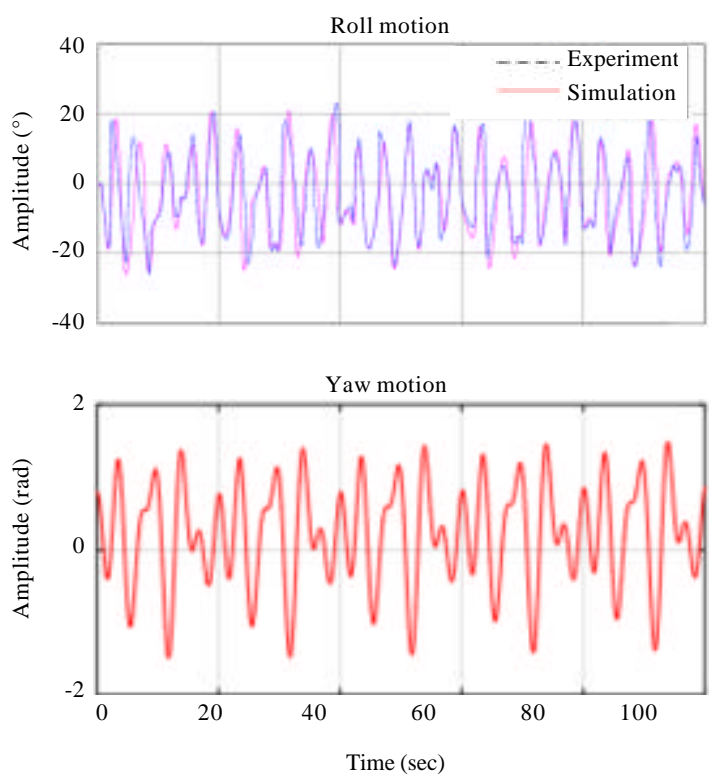



Fig. 3: Computed results of real-time six degree of freedom ship motions

\section{CONCLUSION}

In this study, an overview of MSS is presented. These models are used for predicting the ship motions on waves in real time. The obtained simulation results are good agreement with the experimental data, so, it provides a prompt generating prototype controllers approach created based on simulink diagrams that run in real time on stand-alone computer systems for models scale or full scale systems tests. This also provides the capability of using hardware-in-the-loop simulation. Moreover, this is particularly important for us in education.

\section{ACKNOWLEDGEMENT}

The researchers are grateful to the Weapon Institute, General Department of Defence Industry, Vietnam and Ho Chi Minh City University of Transport for providing necessary research facilities during current research work. We would also like to show our gratitude to CTO S.A. for their supports.

\section{REFERENCES}

Anonymous, 2017. Seakeeping test report for DTMB vessel. CTO, Gdansk, Poland.

Bertram, V., 2012. Practical Ship Hydrodynamics. 2ndEdn., Elsevier, Amsterdam, Netherlands, ISBN: 9780080971520, Pages: 382.

Brunswig, J. and O. El-Moctar, 2004. Prediction of ship motions in waves using RANSE. Proceedings of the 7th Symposium on Numerical Towing Tank (NuTTS 2004), October 3-5, 2004, MARIN, Netherlands, pp: 9-13.

Carrica, P.M., H. Fu and F. Stern, 2011. Computations of self-propulsion free to sink and trim and of motions in head waves of the KRISO Container Ship (KCS) model. Appl. Ocean Res., 33: 309-320.
Fossen, T.I., 2002. Marine Control System-Guidance, Navigation and Control of Ships, Rigs and Underwater Vehicles. Marine Cybernetics Publisher, Trondheim, Norway, ISBN-13:9788292356005, Pages: 570 .

Journee, J.M.J. and W.W. Massie, 2001. Offshore Hydromechanics. 1st Edn., Delft University of Technology, Delft, The Netherlands, Pages: 570.

Journee, J.M.J., 1992. Quick strip theory calculations in ship design. Master's Thesis, Delft University of Technology (TU Delft), Delft, Netherlands.

Kim, K.H. and Y. Kim, 2011. Numerical study on added resistance of ships by using a time-domain Rankine panel method. Ocean Eng., 38: 1357-1367.

Kring, D.C., 1994. Time domain ship motions by a three-dimensional Rankine panel method. Ph.D Thesis, Massachusetts Institute of Technology, Cambridge, Massachusetts, USA.

Newman, J.N., 1992. Panel methods in marine hydrodynamics. Proceedings of the 11th Australasian Conference on Fluid Mechanics, December 14-18, 1992, University of Tasmania, Hobart, Australia, pp: 123-129.

Perez, T., O.N. Smogeli, T.I. Fossen and A.J. Sorensen, 2006. An overview of the Marine Systems Simulator (MSS): A simulink toolbox for marine control systems. Model. Identif. Control, 27: 259-275.

Smogeli, O.N., T. Perez, T.I. Fossen and A.J. Sorensen, 2005. The Marine Systems Simulator State-Space Model Representation for Dynamically Positioned Surface Vessels. In: Maritime Transportation and Exploitation of Ocean and Coastal Resources, Soares, C.G., Y. Garbatov and N. Fonseca (Eds.). CRC Press, Boca Raton, Florida, USA., pp: 748-757.

Soding, H., V. Shigunov, T.E. Schellin and O.E. Moctar, 2014. A Rankine panel method for added resistance of ships in waves. J. Offshore Mech. Arct. Eng., 136: 031601-1-031601-7. 